\title{
Incidence of non-traumatic anterior knee pain among 11 - 17-year-olds
}

\author{
J Phillips (BSc Hons Biokinetics) \\ M F Coetsee (PhD)
}

Department of Human Movement Science, University of Zululand

\begin{abstract}
Objective. To investigate the incidence of anterior knee pain, as well as the effect of sport participation, age of onset and gender differences on the condition.

Design. Questionnaires ( $N=2414$ ), each containing 20 questions, were distributed to 10 - 17-year-old learners at 8 primary and 5 high schools in the Empangeni/Richards Bay area. The return rate was $76 \%$.

Results. Twenty-seven per cent of the respondents reported anterior knee pain. Of these, $21 \%$ experienced pain in the left knee only, $34 \%$ in the right knee only, and $45 \%$ in both knees. Furthermore, $31 \%$ had visited a medical doctor because of the knee pain, $82 \%$ reported that the pain interfered with their sport participation, and $37 \%$ had visited a physiotherapist or biokineticist, of whom $43 \%$ reported that the intervention they received was successful. Previously $37 \%$ of the subjects had taken medication for the condition. The highest incidence of anterior knee pain was reported for 12 and 13-year-old girls and 14 15-year-old boys, which correlates with the period of the adolescent growth spurt. The incidence of anterior knee pain was higher amongst those who participated in sport more than 3 days per week and lower amongst those who participated less than 3 days per week or not at all.

Conclusions. Anterior knee pain is common amongst children between the ages of 10 and 17 years, with a peak during adolescence, especially among girls. Participation in physical activity increases the likelihood of anterior knee pain.
\end{abstract}

\section{CORRESPONDENCE:}

\section{F Coetsee}

Department of Human Movement Science

University of Zululand

Private Bag X1001

kwaDlangezwa

3886

Tel: 035-902 6648

Fax: 035-772 6639

E-mail: mcoetsee@pan.uzulu.ac.za

\section{Introduction}

Anterior knee pain is a common musculoskeletal disorder found in children, adolescents and adults. It frequently interferes with sporting and everyday activities, and as a result a large number of children and adolescents may be forced to limit their physical activity or perform suboptimally on the sports field. The condition may affect up to $25 \%$ of all sportsmen and women. ${ }^{8}$ Cessation of physical activity is detrimental to the developing child as it negatively affects physical development, general fitness, body composition, the development of motor skills, and psychosocial development. ${ }^{6,20}$ It may also lead to the adoption of lifelong sedentary lifestyle habits which poses a health risk in later life.

There is a lack of consensus in the literature, especially in earlier studies, as to the exact definition of the term anterior knee pain. The terms anterior knee pain, patellofemoral pain, chondromalacia patella and patellofemoral arthralgia were used interchangeably in the past. A clinical examination alone may not necessarily identify the source of pain, and costly, invasive procedures are not indicated for most patients. As a result, these nonspecific terms listed above have been used to describe the symptoms of this common clinical condition. ${ }^{5}$ Anterior knee pain is a symptom complex characterised by pain in the vicinity of the patella, which is worsened by sitting, squatting, ascending or descending stairs and vigorous physical activity. 2,4,11,15,18,26,27 The pain can usually be related to the anterior structures of the knee, but is often poorly localised. ${ }^{1,18,26,27,29}$ The condition is often self-limiting, but can take up to 2 years to resolve. ${ }^{20}$ Patellofemoral pain syndrome is a common cause of anterior knee pain, and is said to affect $20 \%$ of the general population, and an even greater percentage of the sporting population. ${ }^{10,12}$ A number of studies have reported that the condition accounts for between $20 \%$ and $40 \%$ of all knee conditions presenting at sports injury clinics. ${ }^{11,14,15,25}$

In this study, the term 'anterior knee pain' was used to describe the symptom complex characterised by pain in the anterior region of the knee during activity and prolonged sitting in the absence of an identifiable pathological condition.

The exact aetiology is unknown but a number of predisposing factors have been suggested as possible causes. 11,32,33 These include overuse, muscle imbalance, muscle tightness, trauma, overweight, genetic predisposition, valgus or varus knee, external tibial torsion, increased $\mathrm{Q}$ - 
angle, abnormal mechanics of the foot and ankle, especially pronation, and generalised ligament laxity. 2,7,15,16,19, 21,22,25,32,34 It has also been suggested that growth-related factors unique to the adolescent population may be important contributing factors in the epidemiology of anterior knee pain. ${ }^{13,30,31}$

Ruffin and Kiningham ${ }^{26}$ reported that of 16748 patients presenting to family doctors with musculoskeletal complaints as a result of a variety of sports participation, $11.3 \%$ had anterior knee pain. The condition may account for $5-10 \%$ of all injuries seen at sports injury clinics. ${ }^{15,33}$ While these studies refer to the general and sporting population, a study by Fairbank et al. ${ }^{7}$ found that 136 of 446 randomly selected pupils from a school of 1850 learners had suffered knee pain in the previous year. At $31 \%$, this is a fairly high incidence. This figure is supported by Harrison et al. ${ }^{10}$ who reported the prevalence in the adolescent population to be $30 \%$. Another study ${ }^{8}$ on school children aged between 10 and 18 years found that as many as $45 \%$ of the cross-section of adolescents had anterior knee pain on physical examination. The authors acknowledge that it is likely that adolescents with the condition would have been more likely to volunteer for the study than those without knee pain. ${ }^{8}$

The aim of the present study was to investigate the incidence of anterior knee pain, the effect of sport participation, age at onset of the condition, gender differences and other factors that could influence the condition among 11 - 17-yearold males and females.

\section{Methods}

A questionnaire consisting of 20 questions, printed in English and Afrikaans was distributed to learners at 8 primary and 5 high schools in the Empangeni/Richards Bay area with permission of the headmaster of each school. All the schools were multi-racial and no distinction was made between race groups. Girls and boys between the ages of 10 and 17 years were eligible for the study. Pupils could complete the questionnaire under the guidance of a researcher or at home with the assistance of their parents, but in most cases it was done in the presence of the researcher in class, thereby reducing the risk of bias. The protocol for the study was approved by the Ethics Committee of the University of Zululand. The questionnaire was designed based on information gleaned from a number of similar studies. ${ }^{8,10,35}$ The majority of questions required the respondent to choose from amongst a number of answers. A few questions allowed space for further explanation.
In order to investigate the incidence of anterior knee pain the subjects were divided into 2 categories, i.e. those with positive anterior knee pain and those who did not have any knee pain. To be classified with positive anterior knee pain the subject had to have met the following criteria while completing the questionnaire: s/he must have indicated the location of the pain on the anterior surface of the knee on the diagram, listed pain in excess of 1 month's duration, indicated the severity of pain as moderate to severe, and indicated that the pain had interfered with sport participation.

\section{Results}

A total of 2414 questionnaires were handed out, of which 1865 were returned, with 33 spoilt or the respondents being younger than 10 years of age. This gave a return rate of $76 \%$. For the purposes of this article 475 subjects were excluded from the study as they had reported previous incidences of traumatic knee injury, and a further 147 were excluded as their answers concerning knee pain were inconclusive. Both these groups of subjects could have fallen into either of the categories used for this article, and their exclusion was therefore necessary.

Table I indicates that $27 \%$ of the sample group had anterior knee pain. Of the subjects who reported anterior knee pain, $21 \%$ experienced it in the left knee only, $34 \%$ in the right knee only, and $45 \%$ in both knees. Thirty-one per cent of subjects had visited a medical doctor because of the knee pain, $82 \%$ reported that the pain interfered with their sport participation, and $37 \%$ had visited a physiotherapist or biokineticist, of whom $43 \%$ reported that the treatment they received was successful. Thirty-seven per cent of the subjects had taken medication for the anterior knee pain. The average duration of pain experienced prior to completion of the questionnaire was 5 months.

Table II indicates the activities and conditions that subjects reported as aggravating their anterior knee pain. Running was the activity that most affected the condition, followed by jumping and kneeling.

In the present study the girls displayed a slightly lower average incidence (26\%) of anterior knee pain than the boys $(30 \%)$ for the age group $10-17$ years. However, when the data for only 12 - 15 years of age was considered the girls displayed a higher incidence of anterior knee pain than the boys (Fig. 1). At age $10-11$ and especially $16-17$ the boys showed a higher incidence of anterior knee pain than the girls.

TABLE I. Number and percentage of subjects per category and per gender $(N=1210)$

\begin{tabular}{|c|c|c|c|c|c|c|}
\hline \multirow[b]{2}{*}{ Category } & \multirow{2}{*}{$\begin{array}{l}\text { Number of } \\
\text { subjects }\end{array}$} & \multirow{2}{*}{$\begin{array}{l}\text { Percentage of } \\
\text { total subjects }\end{array}$} & \multicolumn{2}{|c|}{ Male } & \multicolumn{2}{|c|}{ Female } \\
\hline & & & $N$ & $\%$ & $N$ & $\%$ \\
\hline Positive AKP & 331 & 27 & 142 & 30 & 189 & 26 \\
\hline No knee pain & 879 & 73 & 338 & 70 & 541 & 74 \\
\hline
\end{tabular}




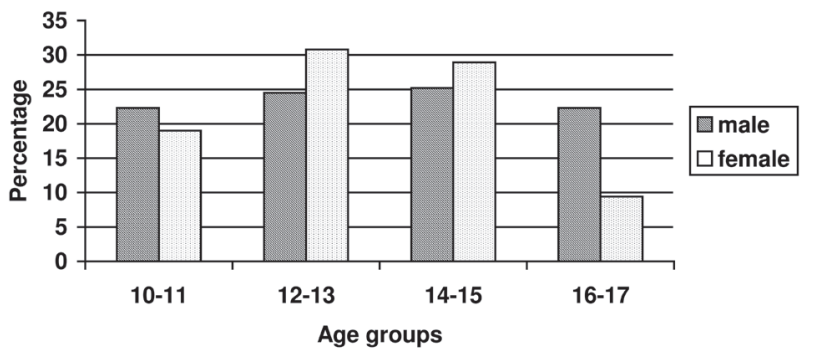

Fig. 1. Percentage of subjects ( $N=1210)$, per age group and gender, displaying anterior knee pain at the time of completing the questionnaire.

The highest incidence for girls was found at 13 years of age, while that for the boys was at 14 years of age. While the girls showed a slight peak in the incidence of anterior knee pain around 12 - 13 years, it was less defined for the boys. However, a chi-square test did not show a significant $(p>0.05)$ dependence between age and pain percentages for males as well as for females. A Mann-Whitney test for independent samples (2-tailed) showed no significant $(p>$ $0.05)$ difference between genders.

Fig. 2 shows the incidence of anterior knee pain amongst the respondents who reported sport participation of different durations. The chi-square test showed a dependency ( $p=$ 0.0000008 ) between frequency of participation and anterior knee pain. A binomial test for percentages to determine whether change in percentage of anterior knee pain was significant as frequency of participation increased (2-sided test at $5 \%$ ) showed a significant increase between 0 v. 1 - 3 times/week $(p=0.00001)$ and $1-3$ v. $3-5$ times/week $(p=$ $0.00726)$. The increases between $3-5$ v. 5 - 7 times/week and 5 - 7 v. $>7$ times/week were non-significant $(p>0.05)$.

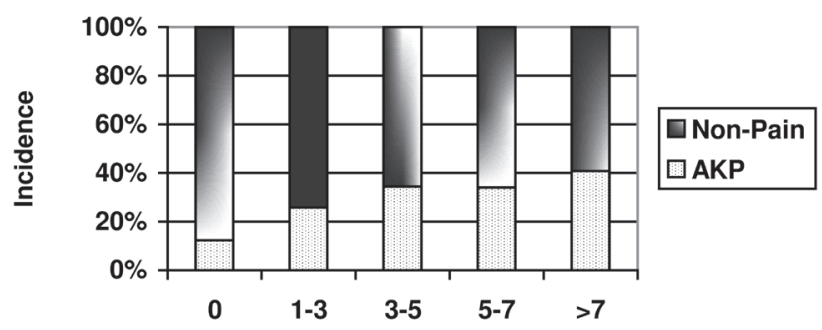

Frequency of sport participation (days/week)

Fig. 2. Influence of sport participation on incidence of anterior knee pain (AKP).

Table III shows the activity profile of respondents according to different sporting codes. Girls with anterior knee pain reported a slightly higher participation in all sporting codes compared with girls with no knee pain. Athletics and swimming were the codes most commonly associated with the condition, followed closely by netball. All sports, except
TABLE II. Activities and conditions reported by subjects to aggravate the anterior knee pain $(N=331)$

\begin{tabular}{ll}
\hline Activity & $\%$ of subjects affected \\
\hline Running & 72 \\
Jumping & 31 \\
Kneeling & 31 \\
Walking & 28 \\
Walking up stairs & 20 \\
Cold weather & 19 \\
Walking down stairs & 14 \\
Standing & 12 \\
Sitting & 7
\end{tabular}

hockey and tennis, resulted in a higher incidence of anterior knee pain amongst the boys. The sports with the highest difference amongst boys were rugby, soccer, athletics and swimming. However, a chi-square test showed no significant $(p>0.05)$ dependence between sport type and anterior knee pain percentages for males as well as for females. A MannWhitney test for independent samples (2-tailed) showed no significant $(p>0.05)$ difference between genders.

\section{Discussion}

The $27 \%$ incidence of anterior knee pain among the sample group (Table I) is comparable to the $20-40 \%$ reported in the literature for this age group. ${ }^{11,14,15,25}$

While little research evidence is presented in the literature, the occurrence of anterior knee pain has been reported as being higher amongst girls. ${ }^{17,18,23,24}$ Goodfellow et al. ${ }^{9}$ reported that the incidence of knee pain in girls compared with boys was 3:2. Contrary to the observations of those authors the present study did not show a significant $(p>$ 0.05 ) difference in incidence of anterior knee pain between girls and boys. The girls displayed a slightly lower average incidence $(26 \%)$ of anterior knee pain than the boys $(30 \%)$ for the age group $10-17$ years. Among the age group 12 - 15 years the girls displayed a higher peak than the boys (Fig. 1). The graph for the boys was much flatter, thereby showing a higher incidence of anterior knee pain during the years 10 - 11 and especially 16 - 17 than the girls. However, none of these differences was significant $(p>0.05)$. The highest incidence of anterior knee pain reported for 12 13-year-old girls and 14 - 15-year-old boys correlates with the period of the adolescent growth spurt. The growth spurt begins at roughly $10.5-11$ years in girls, and $12.5-13$ years in boys, and lasts for approximately 2 years. However, there is wide variation, and the spurt may occur anywhere between 10.5 and 16 years of age. ${ }^{28}$ There does not appear to be consensus on any demonstrable factor causing the peak in anterior knee pain during adolescence. Possible suggestions include hormonal changes and changes directly related to the sudden increase in height. During the spurt, linear growth occurs in the bones first, followed by growth in the soft 
TABLE III. Participation profile (percentage) in specific sports for subjects displaying anterior knee pain (AKP) and subjects with no knee pain

\begin{tabular}{|c|c|c|c|c|c|c|}
\hline & \multicolumn{3}{|c|}{ Males } & \multicolumn{3}{|c|}{ Females } \\
\hline & No knee pain $(N=338)$ & $\operatorname{AKP}(N=142)$ & Difference & No knee pain $(N=541)$ & AKP $(N=189)$ & Difference \\
\hline Athletics & 33 & 44 & +11 & 26 & 41 & +15 \\
\hline Cricket & 44 & 47 & +3 & 2 & 6 & +4 \\
\hline Dancing & 2 & 3 & +1 & 20 & 22 & +2 \\
\hline Gymnastics & 1 & 1 & 0 & 2 & 5 & +3 \\
\hline Hockey & 20 & 17 & -3 & 37 & 43 & +6 \\
\hline Netball & 0 & 0 & 0 & 25 & 34 & +9 \\
\hline Rugby & 40 & 54 & +14 & 0 & 2 & +2 \\
\hline Soccer & 46 & 59 & +13 & 4 & 6 & +2 \\
\hline Squash & 5 & 5 & 0 & 3 & 5 & +2 \\
\hline Swimming & 25 & 39 & +14 & 28 & 40 & +12 \\
\hline Tennis & 12 & 8 & -4 & 10 & 14 & +4 \\
\hline Other & 11 & 16 & +5 & 6 & 10 & +4 \\
\hline
\end{tabular}

tissues. Boys experience reduced flexibility over this period while girls have increased flexibility. ${ }^{20}$ It has been proposed that girls are at a higher risk of joint pain and injury at this stage due to this increased flexibility, and possible ligament laxity or muscle weakness. ${ }^{3}$

Fig. 2 demonstrates that sport participation up to 5 times per week significantly $(p>0.05)$ increased the incidence of anterior knee pain. Participation of more than 5 times per week did not further increase the incidence of anterior knee pain. This seems to support the finding that a higher percentage of subjects with anterior knee pain take part in the different sporting codes, as shown in Table III, than subjects without knee pain even though these differences were nonsignificant $(p>0.05)$. Thus it can be concluded that regular sport participation does increase the risk for anterior knee pain. This finding is supported by the literature where it is stated that the condition is more common among physically active individuals, especially adolescent girls. ${ }^{7,15,27}$ During the adolescent phase the knee structure becomes compromised which predisposes it to injury. This, combined with the added stress during sport participation, could account for the higher incidence of anterior knee pain.

\section{Conclusion}

Anterior knee pain is common amongst 10 - 17-year-olds, with a peak during the ages 12 - 15 years for girls, while the boys showed a more even distribution. Participation in regular physical activity increases the development of anterior knee pain. Cessation of exercise, on the other hand, should not be the preferred course of action as it could negatively influence the development and health status of the individual. Emphasis should rather be on improving non-invasive rehabilitation techniques. Preliminary results show that physiotherapy and biokinetic intervention has a positive effect and it is recommended that this avenue be explored further.

\section{Acknowledgements}

The University of Zululand supported this study financially.

\section{References}

1. Carson WG, James SL, Larson RL, Singer KM, Winternitz WW. Patellofemoral disorders: Physical and radiographic evaluation. Part 1: Physical examination. Clinical Orthopaedics and Related Research 1984; 185 165-77.

2. Cesarelli M, Bifulco P, Bracale M. Quadriceps muscle activation in anterior knee pain during isokinetic exercise. Med Eng Phys 1999; 21: 469-78.

3. Chandy TA, Grana WA. Secondary school athletic injury in boys and girls: A three year comparison. Physician and Sports Medicine 1985; 13: 106-11.

4. Clark DI., Downing N, Mitchell J, Coulson L, Syzpryt EP, Doherty M. Physiotherapy for anterior knee pain: a randomised controlled trial. Ann Rheum Dis 2000; 59: 700-4

5. Crossley K, Bennell K, Green S, Cowan S, McConnell J. Physical therapy for patellofemoral pain: A randomized, double-blinded, placebo-controlled trial. Am J Sports Med 2002; 30: 857-65.

6. Difiori JP. Overuse injuries in children and adolescents. Physician and Sports Medicine 1999; 27(1): 75-89.

7. Fairbank JC, Pynsent PB, van Poortvliet JA, Phillips H. Mechanical factors in the incidence of knee pain in adolescents and young adults. $J$ Bone Joint Surg (Br) 1984; 66: 685-93.

8. Galanty HL, Matthews C, Hergenroeder AC. Anterior knee pain in adolescents. Clin J Sport Med 1994; 4: 176-81.

9. Goodfellow J, Hungerford DS, Zindel M. Patello-femoral joint mechanics and pathology: Functional anatomy of the patello-femoral joint. $J$ Bone Joint Surg Br 1976; 58: 287-99.

10. Harrison E, Quinney H, Magee D, Sheppard MS, McQuarrie A. Analysis of outcome measures used in the study of patellofemoral pain syndrome. Physiotherapy Canada 1995; 47: 264-72.

11. Heng RC, Haw CS. Patello-femoral pain syndrome: Diagnosis and management from an anatomical and biomechanical perspective. Current Orthopaedics 1996; 10: 256-66.

12. Hilyard A. Recent advances in the management of patellofemoral pain the McConnell programme. Physiotherapy 1990; 76: 559-65.

13. Holmes SW, Clancy WG. Clinical classification of patellofemoral pain and dysfunction. Journal of Orthopaedic and Sports Physical Therapy 1998; 28: 299-306.

14. Johnson RP. Anterior knee pain in adolescents and young adults. Curr Opin Rheumatol 1997; 9: 159-64 
15. Kannus $\mathrm{P}$, Niittymaki $\mathrm{S}$. Which factors predict outcome in non-operative treatment of patellofemoral pain syndrome? A prospective follow-up study. Med Sci Sports Exerc 1994; 26: 289-96.

16. Karlsson J, Thomee R, Sward L. Eleven year follow-up of patello-femoral pain syndrome. Clin J Sport Med 1996; 6: 22-6.

17. Lichota DK. Anterior knee pain: symptom or syndrome? Curr Womens Health Rep 2003; 3: 81-6.

18. Nimon G, Murray D, Sandow M, Goodfellow J. Natural history of anterior knee pain: A 14- to 20-year follow-up of non-operative management. $J$ Pediatr Orthop 1998; 18(1): 118-22.

19. O' Neill DB, Michell LJ, Warner JP. Patellofemoral stress: a prospective analysis of exercise treatment in adolescents and adults. Am J Sports Med 1992; 20: 151-6.

20. Patel DR, Nelson TL. Sports injuries in adolescents. Med Clin North Am 2000; 84: 983-1005

21. Pollock D. Clinical examination of the patello-femoral joint. South African Orthopaedic Journal 2004; 3(4): 8-10.

22. Post WR. Patellofemoral pain: Let the physical exam define the treatment. Physician and Sports Medicine 1998; 26(1): 68-79.

23. Powers CM. Rehabilitation of patellofemoral joint disorders: a critical review. Journal of Orthopaedic and Sports Physical Therapy 1998; 28: 34554

24. Price A, Jones J. Chronic traumatic anterior knee pain. Injury 2000; 31 : 373-8.
25. Roush MB, Sevier TL, Wilson JK, et al. Anterior knee pain: a clinical comparison of rehabilitation methods. Clin J Sport Med 2000; 10(1): 22-8.

26. Ruffin MT, Kiningham RB. Anterior knee pain: the challenge of patellofemoral syndrome. Am Fam Physician 1993; 47(1): 185-94.

27. Sandow MJ, Goodfellow JW. Natural history of anterior knee pain in adolescents. J Bone Joint Surg Br 1985; 67(1): 36-8.

28. Sinclair D. Human Growth After Birth. 5th ed. Oxford: Oxford University Press, 1989.

29. Souza DR, Gross MT. Comparison of vastus medialis obliquus: vastus lateralis muscle integrated electromyographic ratios between healthy subjects and patients with patellofemoral pain. Phys Ther 1991; 71: 310-20.

30. Stathopulu E, Baildam E. Anterior knee pain: a long-term follow-up. Rheumatology 2003; 42: 380-2.

31. Teitz CC. The female athlete. J Am Acad Orthop Surg 1997; 5: 89-94.

32. Thomee R, Augustsson J, Karlsson J. Patellofemoral pain syndrome: A review of current issues. Sports Med 1999; 28: 245-62.

33. Wilson T. Anterior knee pain: a new technique for examination and treatment. Physiotherapy 1990; 76: 371-6.

34. Woodall W, Welsh J. A biomechanical basis for rehabilitation programs involving the patellofemoral joint. Journal of Orthopaedic and Sports Physical Therapy 1990; 11: 535-42.

35. Reider B, Marshall JL, Warren RF. Clinical characteristics of patellar disorders in young athletes. Am J Sports Med 1981; 9: 270-6.

\section{Clinical Sports Medicine Medical Management and Rehabilitation, Text with CD-ROM}

\section{ISBN 1416024433 / $9781416024439 \cdot 512$ Pages $\cdot 336$ Illustrations}

\section{Saunders · Published September 2006}

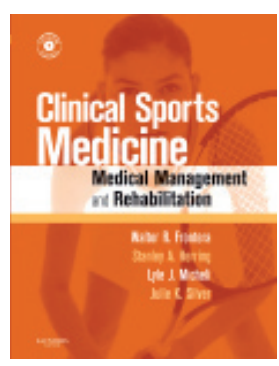

Only a fraction of sports medicine injuries require surgery, but most sports references emphasize surgical management over medical management and rehabilitation.

Clinical Sports Medicine: Medical Management and Rehabilitation is the only comprehensive sports medicine resource to focus on the medical management and rehabilitation of patients. Written by some of the most prominent names in Physical Medicine \& Rehabilitation, this book fills a void by providing an outstanding sports medicine reference aimed at non-surgeons. The international contributors to this book present you with global best practices from world leaders in the field. The main focus lies on the practical information you need to implement the most effective non-surgical management and rehabilitation approaches for today's diverse patient population. 